\title{
A Game Theoretic Sensor Resource Allocation Using Fuzzy Logic
}

\author{
Stephen C. Stubberud ${ }^{1}$ and Kathleen A. Kramer ${ }^{2}$ \\ ${ }^{1}$ Oakridge Technology, Del Mar, CA 92014, USA \\ ${ }^{2}$ Engineering Department, University of San Diego, San Diego, CA 92110, USA \\ Correspondence should be addressed to Kathleen A. Kramer; kramer@sandiego.edu
}

Received 27 October 2012; Revised 13 February 2013; Accepted 13 February 2013

Academic Editor: Richard Jensen

Copyright (C) 2013 S. C. Stubberud and K. A. Kramer. This is an open access article distributed under the Creative Commons Attribution License, which permits unrestricted use, distribution, and reproduction in any medium, provided the original work is properly cited.

\begin{abstract}
A sensor resource management system that employs fuzzy logic to provide the utility functions to a game theoretic approach is developed. The application looks at a virtual fence problem where several unattended ground sensors are placed in remote locations to act as virtual sentries. The goal of the approach is to maximize the battery life while tracking targets of interest. This research also considers the incorporation of uncertainty into the fuzzy membership functions. Both type-2 fuzzy logic and the use of conditional fuzzy membership function are employed. The type-2 fuzzy logic is employed in the case of acoustical sensor tracking accuracy degradation, while the condition-based membership functions are used to adapt to different conditions, such as environmental conditions and sensor performance degradation, over time. The resource management process uses fuzzy logic to determine which of the sensor systems on a sensor pod is used to provide initial classification of the target and which sensor or sensors are to be used in tracking and better classifying the target if it is determined to be of value to the mission. The three different approaches are compared to determine when the best times for the more complex approaches are warranted.
\end{abstract}

\section{Introduction}

A resource allocation technique for extending the battery life of unattended ground sensors (UGS) while still providing tracking and classification capabilities can be applied to the increasingly remote monitoring activities of UGS systems. Fuzzy logic approaches to this resource allocation can incorporate fixed membership functions $[1,2]$ and be advanced by applying type-2 fuzzy logic [3], or conditional fuzzy membership functions can be used to model the sensors' capabilities.

The use of UGS has become increasingly necessary in environmental protection and other applications, as noted in $[4,5]$. In remote locations, the use of on-site personnel to monitor illegal or dangerous activities is too costly economically and can be physically impractical. These activities, such as illegal mining [6], illegal cultivation [7], illegal logging [8], poaching, dumping of toxic chemicals, criminal activity [9], for example, smuggling, and recreational uses [10], such as shooting and off-highway vehicle use where such use is illegal and causes severe environmental damage, are becoming more common. Gates, fences, and signs have proven ineffective at discouraging much of this illegal use [11].

To provide a continual monitoring presence and be able to deploy sparse enforcement resources have required the employment of virtual fences or virtual sentries. One such approach to this is to deploy networks of UGS similar to those of the Rheinmetall Defense BSA UGS [12] in Figure 1. These sensor platforms can have multiple sensors on them to provide various capabilities such as identification, kinematic tracking, and redundancy.

Continual operation of these sensors would quickly drain the batteries that power the systems. This would make such sensor networks useless, as they would need several service calls in a month time, which would also reduce their covertness and increase the cost of their operation. Simple feed-forward control, where a simple trigger would activate the sensors, would reduce the battery power consumption but would not make intelligent decision on when a sensor or a UGS should be activated for actual and potential and remain off for targets of little concern. 
In an intelligent technique, a wake-up sensor would initiate the operations of all the sensors on the UGS for any passing vehicle. However, in cases such as logging protection, small all-terrain vehicles (ATVs) and cars would not be of interest while a pick-up truck may be of some concern. Larger vehicles, such as semitrailers and small flatbed tracks, would be of greater concern. Therefore, sensor resources are used intelligently, and battery utilization is reduced, which increases the time between maintenance.

A game-theoretic control approach to an intelligent technique using fuzzy logic is shown in Figure 2. The algorithmic process uses a wake-up procedure to identify the target and then determine which, if any, of the sensors is implemented for full identification and target tracking. This approach is an extension of that developed in $[1,3]$ where the algorithm was used to determine if each of the sensors was to be deployed independently based on the mission importance of the target, the remaining battery power, and the sensor's capabilities. However, the determination of all of the sensors operating simultaneously is not made as a single decision. Game theoretic approaches to control an entire network, as opposed to individual sensors, have been tried in other approaches, notably [5]. The algorithm is evaluated using fixed fuzzy memberships, type-2 fuzzy logic [13], and conditional fuzzy membership functions [14], the latter two which were incorporated to handle a variety of implementation and environmental issues that the UGS will encounter.

In Section 2, the basic game theoretic technique is detailed. The process is started as a general concept that is expanded to the step-by-step functional process. Then the elements of the fuzzy logic and game implementation are presented. Section 3 extends the technique to incorporate type- 2 fuzzy logic. This is followed in Section 4 with a description of the incorporation of conditional fuzzy membership functions. Section 5 overviews the scenario and conditions used to obtain the results of the battery power consumption and sensor selection presented in Section 6. These results will also include a number of different initial conditions on the battery level.

\section{Fuzzy Game Approach}

The general process of the resource allocation described in Figure 3 has two main elements. The first is to "wake up" the UGS. A wake-up sensor detects an approaching target and initiates the process. A selection of the initial classification sensor is made. Each UGS has two such sensors. This decision has an effect on the remaining battery power as the selected sensor drains the battery.

So there are three possible moves:

$$
S_{w}=\left(\text { Sensor }_{1}, \text { Sensor }_{2} \text {, No_sensor }\right)
$$

with the expected payoff being

$$
u_{w}^{i}=\left[\begin{array}{c}
\text { classify_tgt }_{i} \\
\text { drain_battery }_{i}
\end{array}\right] .
$$

The payoff is how much battery power is drained in exchange for the probability of correctly identifying the target. As the

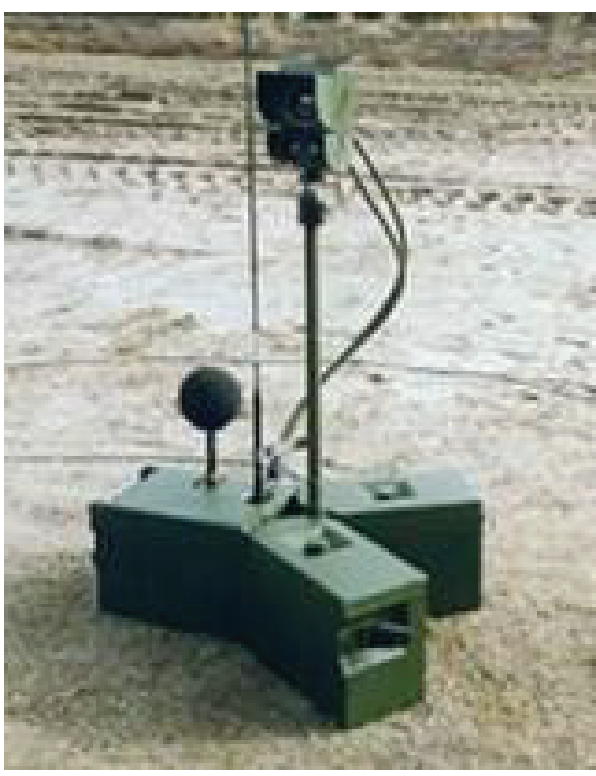

FIGURE 1: Rheinmetall Defense BSA UGS with video capability (Source: Defense Update, 2006).

battery's power is reduced, the power consumption becomes more important in the decision process. If neither sensor is selected, then the target is missed and the next step is skipped.

If a sensor is activated, the system determines a level of mission importance by classifying the target. The second move in the game is to determine whether the target should be tracked and better identified. Now four possible moves are available:

$$
S_{\text {trk }}=\left(\text { Sensor }_{1}, \text { Sensor }_{2}, \text { Sensors }_{1 \& 2} \text {, No_sensor }\right)
$$

with the expected payoff being

$$
u_{\text {trk }}^{i}=\left[\begin{array}{c}
\text { perform_mission }_{i} \\
\text { drain_battery }_{i}
\end{array}\right],
$$

where perform mission is a function

$$
\begin{aligned}
& \text { perform_mission }_{i} \\
& \quad=f \text { (mission_importance, classification, kinematics) } .
\end{aligned}
$$

In both cases, the payoff has a benefit and a cost that will be used to create the overall score of each move. The cost and benefits are modified using the fuzzy logic engines.

The fuzzy resource allocation algorithms are detailed in Figures 4 and 5. The wake-up algorithm shown in Figure 4 is a subset of the overall allocation algorithm. It has three inputs: battery power remaining, battery usage of the sensor, and classification accuracy of the sensor. Using the fuzzy memberships functions of Figure 6, the three inputs are mapped so they may be applied to the fuzzy inference engines. The classification accuracy is processed using the inference engine and consequent membership functions of Figure 7. This provides the benefit to the game selection. 


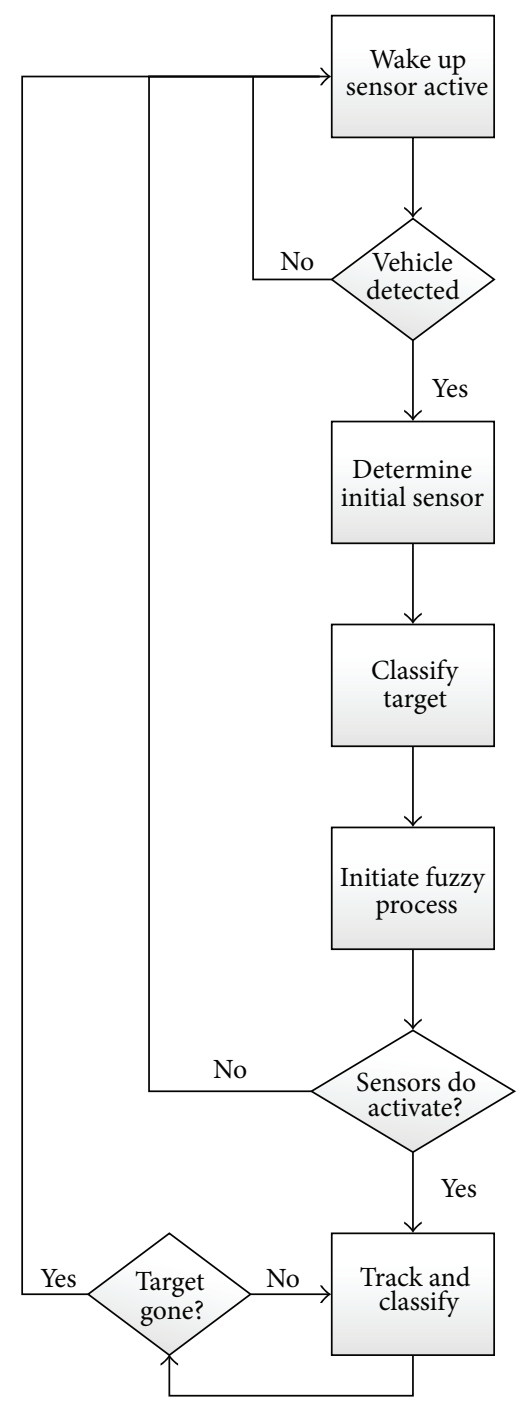

FIGURE 2: Battery consumption approach to sensor activation.

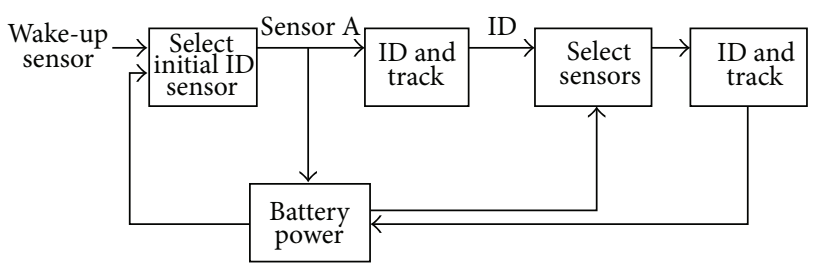

Figure 3: Fuzzy resource allocation technique.

The battery level and power consumption are mapped and processed as a two-input fuzzy logic system, as seen in Figure 8 . This result is the cost for the game process. The game generates a score. The highest scoring sensor selection is then compared to a threshold and activated if the threshold is exceeded.

Once the target is classified, a mission importance score is given to the target. The algorithm of Figure 5 is then applied to the UGS sensors. Based on the capabilities of the sensors

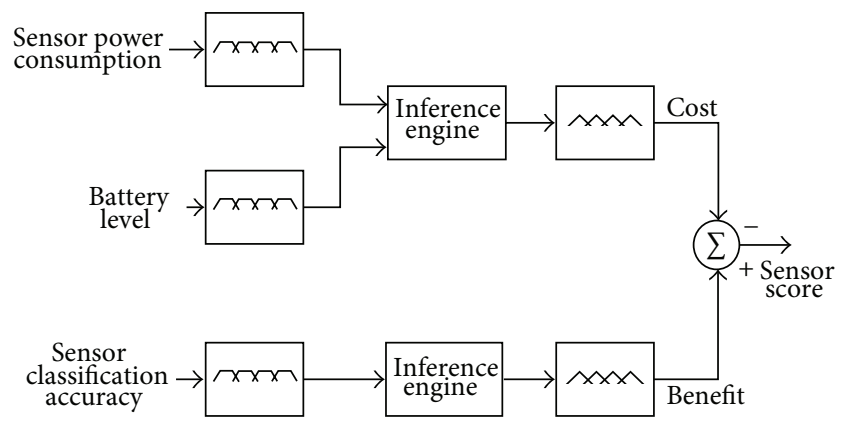

FIGURE 4: Wake-up algorithm uses initial classification to select tracking sensors.

(both kinematic and classification), the mission importance of the target, and the battery information, a score is generated for each individual sensor and the combination of both sensors. The battery usage and power level are the same process as used in the wake-up process. The benefit score is generated by two scores: the kinematic and mission importance score and the classification and mission importance score which utilizes the inference engine and consequent membership functions in Figure 9. The highest score is then used to compare against the threshold. If the threshold is attained or surpassed, then that selection is implemented to track and identify the target.

The results of the two functions are differenced to provide a score. If the target is assumed to be of interest, then the sensor selection system determines which sensors will be used for target tracking and classification. Unlike in [1], four different moves are possible for the two sensor UGS. In this case, none, either, or both sensors can be employed. The fuzzy process is a straightforward extension of the wake process in that it incorporates the tracking capabilities and the mission importance in the benefit value calculation.

The game approach is a more complex technique than was applied in $[1,3]$ where a simple game was generated for each sensor. For the wake-up and quick classification portion of the resource manager, the score for each sensor on the UGS was given as

$$
\operatorname{score}_{w}^{i}=\text { score }_{\text {classification }}-\text { score }_{\text {power_consumption }} .
$$

The highest scoring sensor was chosen as the initial classification sensor. The score was then compared to the threshold. If the threshold was met, the sensor was turned on. Otherwise, the target was ignored. For the tracking each sensor was given a score

$$
\begin{aligned}
\text { score }_{\text {trk }}^{i}= & \text { score }_{\text {classification }}+\text { score }_{\text {kinematics }} \\
& - \text { score }_{\text {power_consumption. }} .
\end{aligned}
$$

Each sensor's score was compared against the threshold, and, if it were met, then the sensor was activated for tracking and classification. 


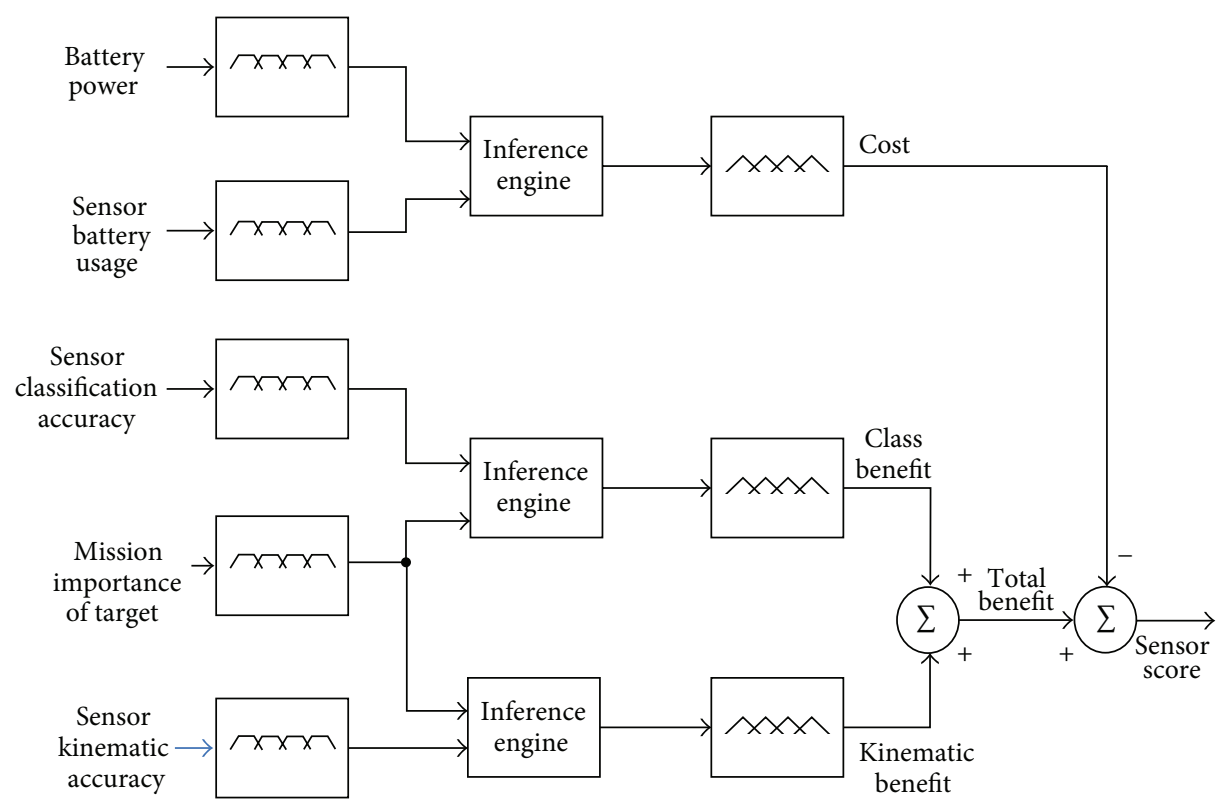

FIGURE 5: Fuzzy resource allocation technique for target tracking and classification.

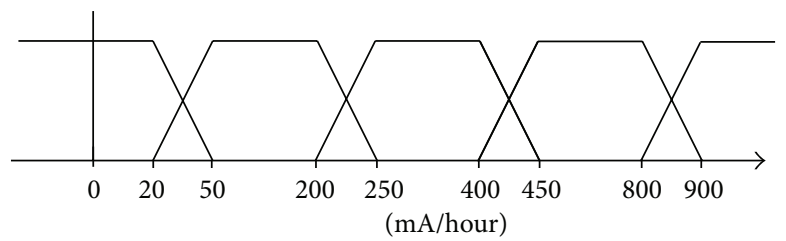

(a)

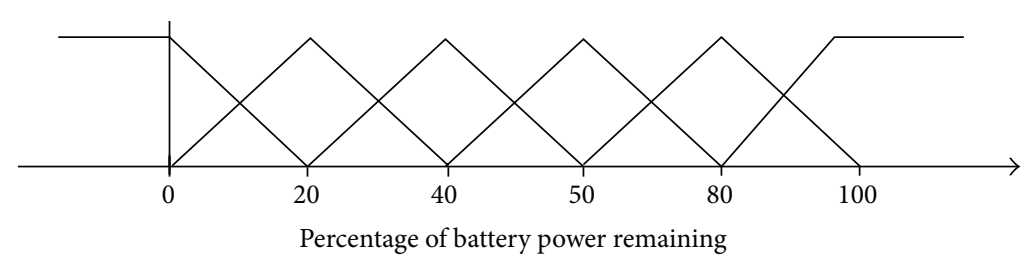

(b)

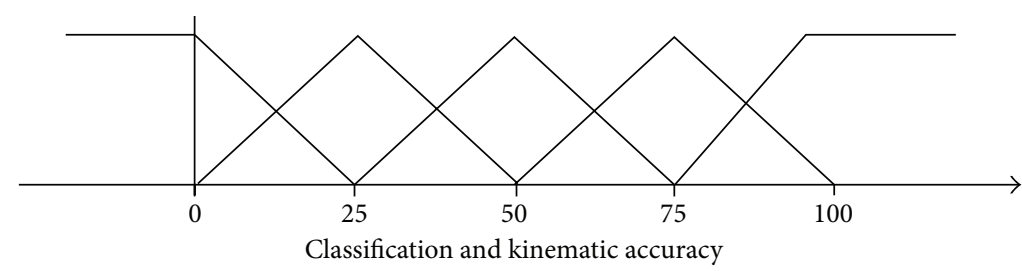

(c)

FiguRE 6: Antecedent membership functions used for the wake-up classification's fuzzy game and in the sensor tracking and classification fuzzy game.

The scoring algorithm for the tracking sensor selection was modified from that used in [2]. Each sensor had a score generated, as did both sensors operating. The selection (a single sensor or both sensors) with the highest score was compared to the threshold. If the selection met or exceeded the threshold, then that selection was used and the appropriate sensor or both sensors were activated. The new scoring algorithm is given as

$$
\begin{aligned}
\text { score }_{\text {trk }}^{i} & =\text { weight }_{\text {class }} \cdot \text { score }_{\text {classification }} \\
& + \text { weight }_{\text {kinematics }} \cdot \text { score }_{\text {kinematics }} \\
& - \text { weight }_{\text {power }} \cdot \text { score }_{\text {power_consumption }},
\end{aligned}
$$




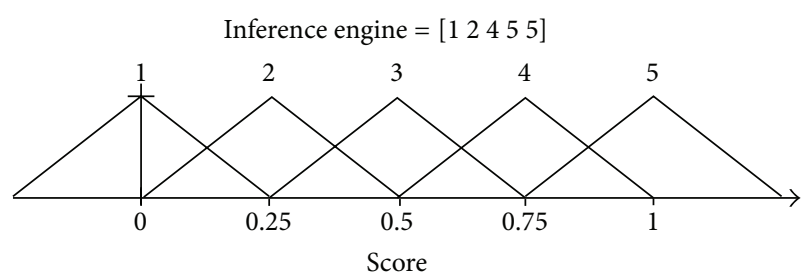

FIGURE 7: Inference engine and consequent membership functions sensor classification accuracy.

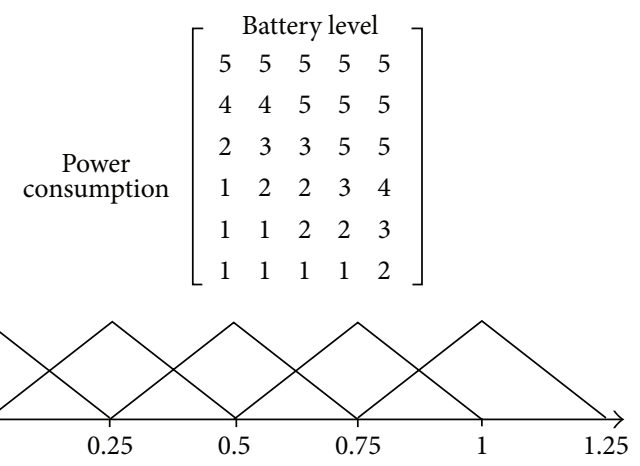

FIGURE 8: Inference engine and consequent membership functions for battery power and consumption are used for both wake-up and tracking resource allocation.

where

$$
\begin{aligned}
\text { weight }_{\text {class }} & =0.5, \\
\text { weight }_{\text {kinematics }} & =1.5, \\
\text { weight }_{\text {power }} & =4.2 \cdot\left(1-\frac{\text { pct }_{\text {power }}}{100}\right) .
\end{aligned}
$$

The choice of two sensors is made on the overall improvement of using two sensors where the improvement is not linear but made through a probabilistic combination.

\section{Type-2 Fuzzy Logic as Applied to System Uncertainty}

When UGS system is actually deployed, many different issues that can affect performance may arise. An acoustic sensor array is expected to be placed in a straight line, as seen in Figure 10, that yields the expected time difference of arrival spacing. It may be placed poorly or, because of impact from animals or water runoff, be moved and have a placement more like the examples of Figure 11. Such placements distort the acoustic beams from the modeled uncertainties to something very different. Figure 12 shows the distinctive pattern of uncertainty for an array such as in Figure 10, but, with configurations like those in Figure 11, the uncertainty pattern could be significantly distorted.

Acoustic signals might also be distorted by echoes and by environmental changes as simple as temperature variations

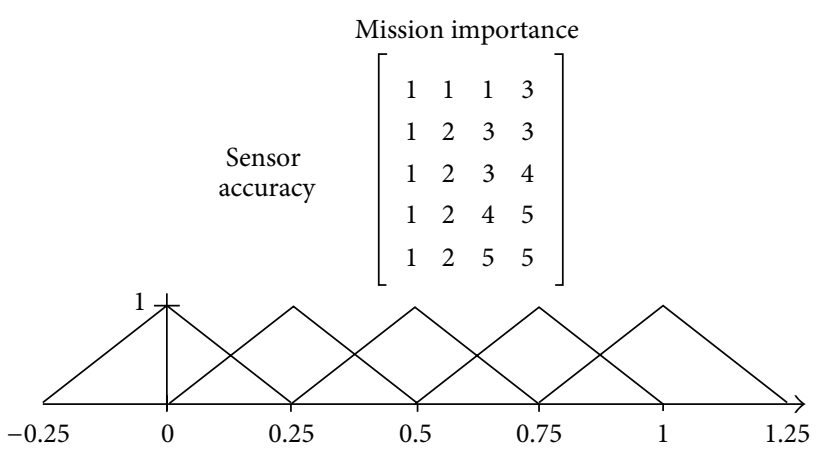

FIGURE 9: The inference engine of the sensor capability and mission importance creates the relationship between the consequent membership functions and the antecedent membership function for both classification and kinematic capabilities of the sensors.

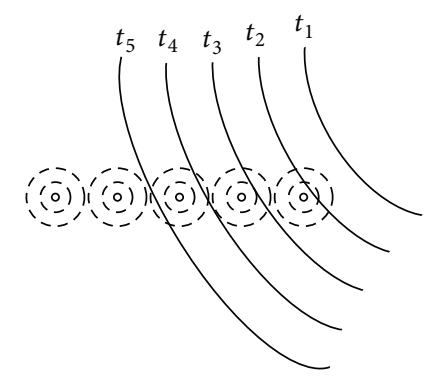

FIGURE 10: Linearly placed receivers result in even time difference of arrival spacing.

and humidity factors. The electrooptical (EO) sensor can have its lens contaminated by particulate matter or by glare during some times of the day. If the UGS system had a solar charger, the performance of the panel varies by time of year, time of day, weather, and by the buildup of dirt and dust.

All of these issues affect the uncertainty of the sensor model. These variations would be difficult to model mathematically and do affect the membership functions used in the resource manager. One method to consider for these issues is to use type-2 fuzzy logic [13].

To simplify the discussion, the focus will be on the uncertainty (or quality) of the acoustic sensor for kinematic accuracy. According to [15], type-2 fuzzy sets can be considered a fuzzy-fuzzy set with both an upper membership function and a lower membership function, as seen in Figure 13. The region between the membership functions is referred to as the footprint of uncertainty (FOU). The weighting of the uncertainty can be either uniform or nonuniform. The difference in application of the type-2 fuzzy set is in the processing, depicted in Figure 14.

In this application, the acoustic sensor is assumed to be placed somewhat accurately as linear array. The array elements may be moved over time between maintenance of 


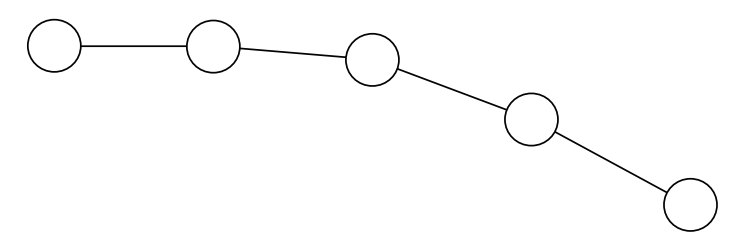

(a)

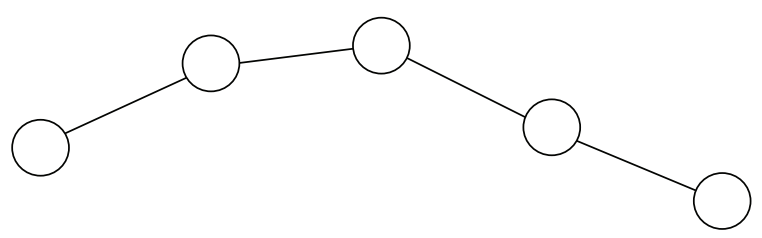

(b)

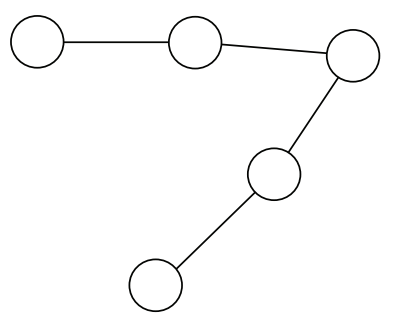

(d)

FIGURE 11: Sensor arrays are often improperly deployed with patterns that are not the linear array formation.

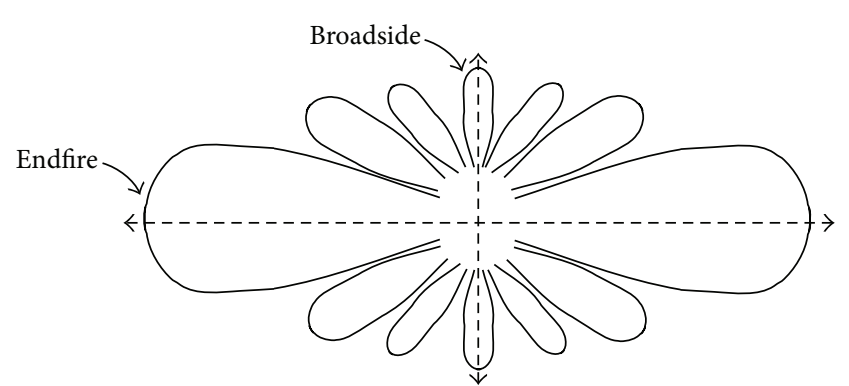

FIGURE 12: Uncertainty of linear array has distinctive pattern and is much greater towards the endfire.

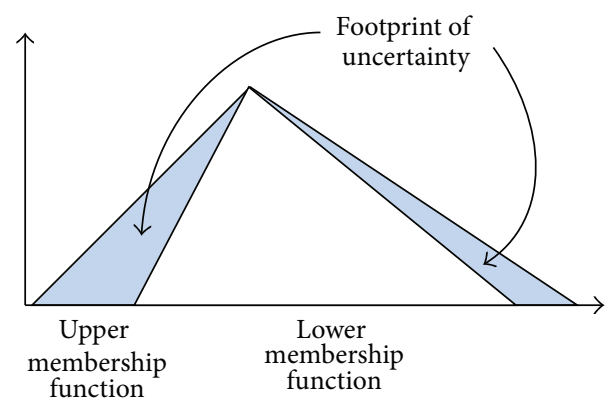

FIGURE 13: type-2 fuzzy set.

the UGS. Also, the local environment may have a deleterious effect on the sensors' performance. For such reasons, the baseline fuzzy set used in [2] may not be accurate. Therefore, the type- 2 model is used for the acoustic sensor in the kinematic accuracy portion of the system described in Figure 10. While a complex model for the FOU could be developed based on the location, environment, and time that the UGS remains in the field without maintenance, for this effort, a uniform function time-invariant model is employed.

\section{Conditional Fuzzy Logic for System Uncertainty}

In [14], a technique was described to change the operating parameters used in the modeling of a system operating in different modes. By using fuzzy logic, the parameters were modified to better model the system in the current operation profile. With the UGS system, the operation profile of the system changes (usually deteriorates) between maintenance cycles. With degradation, the fuzzy membership functions of the various sensors would change over time. In [14], the concept was to adapt the parameters of the fuzzy membership functions based on conditions of the system. While that approach has merit for this application, a modification to the approach is considered. The input values to the antecedent membership functions described in Figure 6 were originally considered fixed. These values would vary as the environmental conditions change. In Section 3, the conditions and examples that were described remain relevant as sources of uncertainty.

In this effort, the EO sensor is the sensor of focus for this approach. Over time, the EO sensor's lens can become impacted by rain and dust. Once clear images used by classification algorithms are now blurred and obscured. The complexity of the environment can be modeled in a number of ways. A UGS system needs to remain simple to reduce computational load and power consumption. For this reason, the model to modify classification accuracy membership function is a straightforward two-input model based on the time of year and the length of time between maintenance cycles. It is depicted in Figures 15-18. Figure 15 denotes the four seasons. Note that this is a circular function, as winter crosses both the beginning and the end of the values. Figure 16 denotes the time since maintenance. Assuming a 2-4-month cycle for repairs, the membership functions start in small increments and become larger as time goes on. The inference engine is shown in Figure 17. The output function (Figure 18) creates a quality value for the sensor. Thus, if the system has been operating for 5 weeks in winter, the resulting 


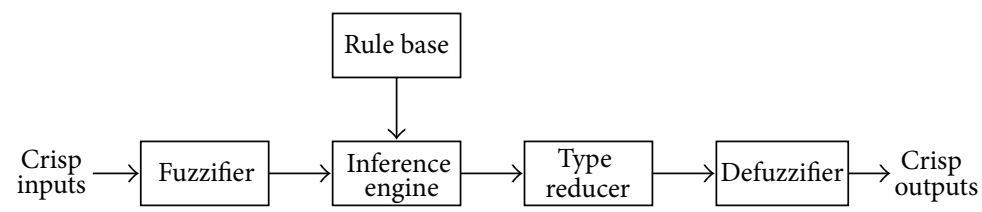

Figure 14: Interval type-2 fuzzy logic processing.

TABLE 1: Target detection scenario values.

\begin{tabular}{|c|c|c|c|c|c|c|}
\hline \multirow{2}{*}{ Target set } & \multirow{2}{*}{ Mission imp. } & \multicolumn{5}{|c|}{ Detection time range } \\
\hline & & UGS 1 & UGS 2 & UGS 3 & UGS 4 & UGS 5 \\
\hline (1) Day 1 & 68 & $12: 30-12: 35$ & $12: 33-12: 46$ & $12: 40-12: 47$ & $12: 43-13: 00$ & ND \\
\hline (2) Day 1 & 84 & $16: 00-16: 10$ & $15: 57-16: 04$ & $15: 51-15: 58$ & ND & $15: 47-15: 55$ \\
\hline (3) Day 4 & 20 & $02: 17-02: 22$ & $02: 23-02: 27$ & $02: 25-02: 28$ & $02: 26-02: 31$ & ND \\
\hline (4) Day 5 & 92 & 09:21-09:31 & $09: 26-09: 37$ & $09: 28-09: 40$ & ND & 09:33-09:52 \\
\hline (5) Day 5 & 12 & ND & $11: 21-11: 22$ & 11:21-11:30 & $11: 15-11: 23$ & $11: 24-11: 34$ \\
\hline (6) Day 7 & 38 & ND & $11: 15-11: 24$ & $11: 18-11: 35$ & $11: 08-11: 25$ & $11: 30-11: 45$ \\
\hline (7) Day 8 & 62 & $16: 00-16: 10$ & $15: 57-16: 04$ & $15: 51-15: 58$ & ND & $15: 47-15: 55$ \\
\hline
\end{tabular}

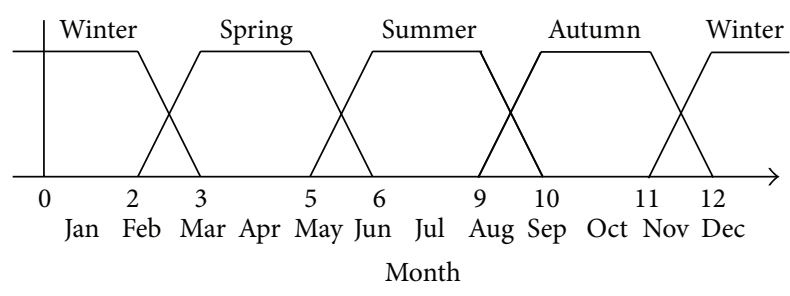

FIGURE 15: Mapping of months into four seasons.

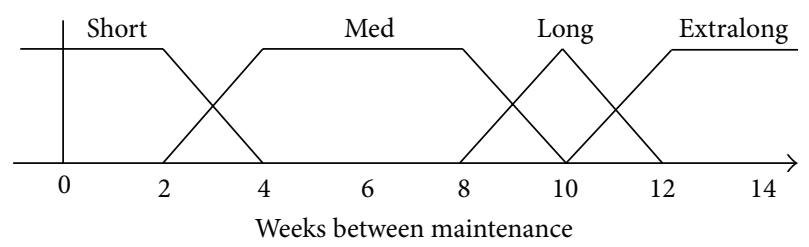

FIGURE 16: Weeks between maintenance mapping into categories.

EO sensor would be rated as having 0.7 as opposed to its standard 0.89 for target classification.

\section{Scenario}

A scenario is used to evaluate this algorithm based upon that in $[1,3]$. This allows comparison of the new technique developed with previous results.

A trail system resembling an important logging and fire road intersection has been developed and is shown in Figure 19. Two different sensor pods are considered. Each pod type has an acoustic array and an acoustic wake-up sensor. The wake-up sensor is simply a trip alarm or proximity detector. The acoustic array is primarily used for target localization but can also provide classification information. This data will inform the authorities of which way a vehicle is traversing the area. Sensor pod type-1 uses a chemical sensor

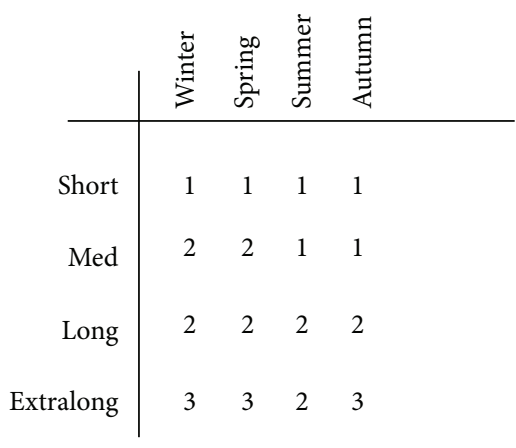

FIGURE 17: Inference engine based upon season and time since maintenance.

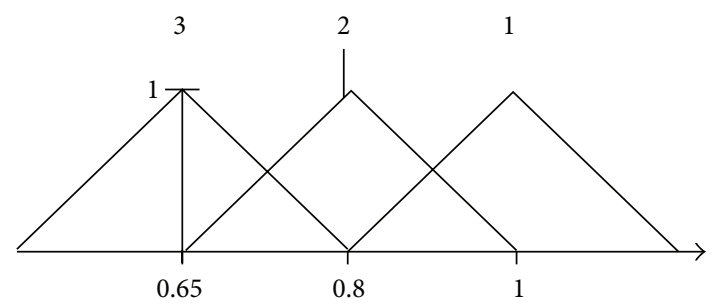

FIGURE 18: Quality value for sensor based upon inference engine result.

to identify the target. The pod type- 2 has an electrooptical (EO) sensor that can provide both tracking information and classification information. (The targets being tracked in this case are assumed to be on the road network.)

Table 1 describes the seven targets as they traverse the region of interest. Using a gametheoretic approach, fed by fuzzy logic, a multisensor system was tasked with classification and tracking of mission critical targets over a ten-day period. In this scenario, mission critical targets are larger trucks. ATVs and cars are smaller vehicles that are not 
TABLE 2: Mapping of sensor capabilities to their fuzzy antecedent measurement function.

\begin{tabular}{lcccc}
\hline Sensor & $\begin{array}{c}\text { Target class. quality } \\
(0-100)\end{array}$ & $\begin{array}{c}\text { Attribute class. quality } \\
(0-100)\end{array}$ & $\begin{array}{c}\text { Localization quality } \\
(0-100)\end{array}$ & $\begin{array}{c}\text { Power usage } \\
(\mathrm{mA} / \mathrm{hr})\end{array}$ \\
\hline Acoustic wake-up (1) & 2 & 2 & 5 & 3 \\
Acoustic (2) & 28 & 68 & 70 & 380 \\
Chemical (3) & 28 & 45 & 5 & 12 \\
Electooptical (4) & 72 & 84 & 95 & 610 \\
Chemical/acoustic pair & 38 & 82 & 70 & 492 \\
EO/acoustic pair & 89 & 98 & 99 & 990 \\
\hline
\end{tabular}

TABLE 3: Condition-based mapping of sensor capabilities to their fuzzy antecedent measurement function based on season and time from last maintenance.

\begin{tabular}{lcccc}
\hline Sensor & $\begin{array}{c}\text { Target class. quality } \\
(0-100)\end{array}$ & $\begin{array}{c}\text { Attribute class. quality } \\
(0-100)\end{array}$ & $\begin{array}{c}\text { Localization quality } \\
(0-100)\end{array}$ & $\begin{array}{c}\text { Power usage } \\
(\mathrm{mA} / \mathrm{hr})\end{array}$ \\
\hline Acoustic wake-up (1) & 2 & 2 & 5 & 3 \\
Acoustic (2) & 28 & 68 & 70 & 380 \\
Chemical (3) & 28 & 45 & 52 & 70 \\
Electooptical (4) & 55 & 82 & 70 & 610 \\
Chemical/acoustic pair & 38 & 70 & 85 & 492 \\
EO/acoustic pair & 70 & & 92 & 990 \\
\hline
\end{tabular}

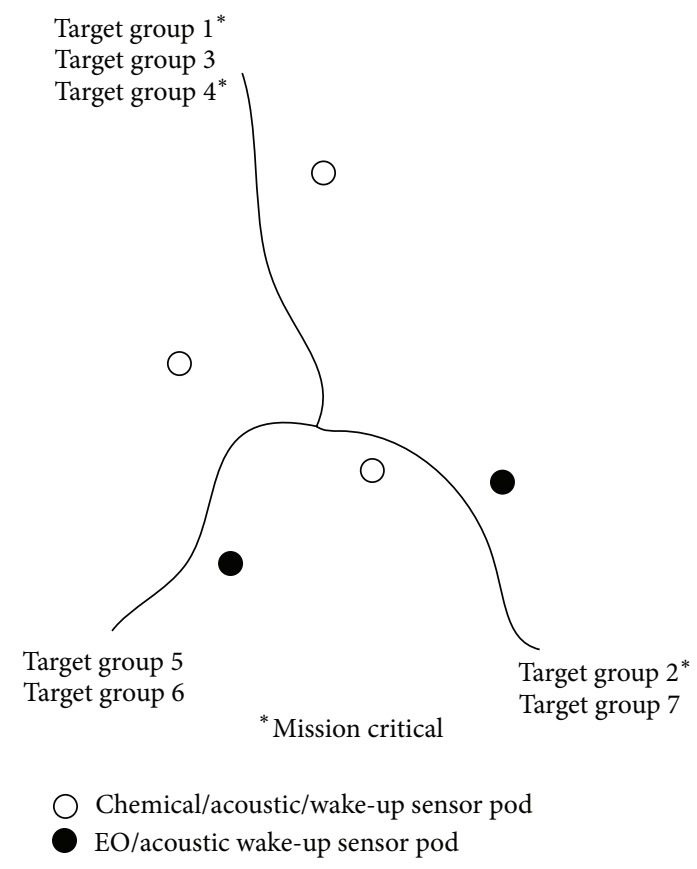

Figure 19: Multisensor scenario with five sensor pods.

important. Pickup trucks are considered of possible concern. The example scenario in Figure 19 combines five sensors pods, each with an acoustic array and an acoustic wake-up sensor, including three of type-1 that have chemical sensor systems and two of type-2 with electrooptical sensor systems. UGS pods $1-3$ are of type- 1 and UGS pods 4 and 5 are of type2.
Based on the sensors chosen for use in the scenario, Table 2 defines the baseline capabilities of each of the four types of sensors involved in the sensor pods. There are two classification ratings: target and attribute. The first is to provide actual classification of a target, such as would be provided by an automatic target recognition (ATR) system. The thresholds that were chosen for the sensor selections were 0.02 for the wake-up sensor and 0.9 for the tracking sensors. An ATR system usually uses a single sensor report to determine the target class [16]. The second rating is that of attribute classification where a sensor provides piece of information that can be fused with other data to provide a classification [17]. The next two ratings are for localization rating and power usage.

Table 3 provides a condition-based modification to the baseline fuzzy logic for the resource management system that takes into account season and time between maintenance conditions from Figures 15-18. These new numbers for the $\mathrm{EO}$ are from a winter and 7 weeks from maintenance time.

\section{Results}

The resource management system was implemented using the aforementioned fuzzy logic and parameters. The goal was to monitor the power usage for the scenario and determine which sensors were used for the wake-up process and for the tracking process. Six separate initial conditions were employed for the battery power. These included an initial charge of $100 \%, 90 \%, 80 \%, 65 \%, 50 \%$, and $45 \%$. Results were obtained using three different variations on the system: fixed fuzzy logic, type-2 fuzzy logic, and a condition-based fuzzy logic system.

The fixed fuzzy logic system is the baseline resource system applied to the scenario described in the previous 
TABLE 4: (a) Selection of wake-up sensor at UGS for fixed, type-2, and condition-based fuzzy logic: target 1. (b) Selection of wake-up sensor at UGS for fixed, type-2, and condition-based fuzzy logic: target 4. (c) Selection of wake-up sensor at UGS for fixed, type-2, and condition-based fuzzy logic: target 6.

(a)

\begin{tabular}{|c|c|c|c|c|c|c|c|c|c|c|c|c|c|c|c|}
\hline \multirow{3}{*}{ Initial batt. power } & \multicolumn{3}{|c|}{ UGS 1} & \multicolumn{3}{|c|}{ UGS 2} & \multicolumn{3}{|c|}{ UGS 3} & \multicolumn{3}{|c|}{ UGS 4} & \multicolumn{3}{|c|}{ UGS 5} \\
\hline & \multicolumn{3}{|c|}{ Type-1 } & \multicolumn{3}{|c|}{ Type-1 } & \multicolumn{3}{|c|}{ Type-1 } & \multicolumn{3}{|c|}{ Type-2 } & \multicolumn{3}{|c|}{ Type-2 } \\
\hline & $\mathrm{F}$ & $\mathrm{T} 2$ & $\mathrm{CB}$ & $\mathrm{F}$ & $\mathrm{T} 2$ & $\mathrm{CB}$ & $\mathrm{F}$ & $\mathrm{T} 2$ & $\mathrm{CB}$ & $\mathrm{F}$ & $\mathrm{T} 2$ & $\mathrm{CB}$ & $\mathrm{F}$ & $\mathrm{T} 2$ & $\mathrm{CB}$ \\
\hline $100 \%$ & 2 & 2 & 2 & 2 & 2 & 2 & 2 & 2 & 2 & 4 & 4 & 2 & NA & NA & NA \\
\hline $90 \%$ & 2 & 2 & 2 & 2 & 2 & 2 & 2 & 2 & 2 & 4 & 4 & 2 & NA & NA & NA \\
\hline $80 \%$ & 2 & 2 & 2 & 2 & 2 & 2 & 2 & 2 & 2 & 4 & 4 & 2 & NA & $\mathrm{NA}$ & NA \\
\hline $65 \%$ & 2 & 2 & 2 & 2 & 2 & 2 & 2 & 2 & 2 & 4 & 4 & 2 & NA & NA & NA \\
\hline $50 \%$ & 2 & 2 & 2 & 2 & 2 & 2 & 2 & 2 & 2 & 2 & 2 & 2 & NA & NA & NA \\
\hline $45 \%$ & 3 & 3 & 3 & 3 & 3 & 3 & 3 & 3 & 3 & 2 & 2 & 2 & NA & NA & NA \\
\hline
\end{tabular}

Fuzzy logic: fixed (F), type-2 (T2), or cond.-based (CB).

(b)

\begin{tabular}{|c|c|c|c|c|c|c|c|c|c|c|c|c|c|c|c|}
\hline \multirow{3}{*}{ Initial batt. power } & \multicolumn{3}{|c|}{ UGS 1} & \multicolumn{3}{|c|}{ UGS 2} & \multicolumn{3}{|c|}{ UGS 3} & \multicolumn{3}{|c|}{ UGS 4} & \multicolumn{3}{|c|}{ UGS 5} \\
\hline & \multicolumn{3}{|c|}{ Type-1 } & \multicolumn{3}{|c|}{ Type-1 } & \multicolumn{3}{|c|}{ Type-1 } & \multicolumn{3}{|c|}{ Type-2 } & \multicolumn{3}{|c|}{ Type-2 } \\
\hline & $\mathrm{F}$ & $\mathrm{T} 2$ & $\mathrm{CB}$ & $\mathrm{F}$ & $\mathrm{T} 2$ & $\mathrm{CB}$ & $\mathrm{F}$ & $\mathrm{T} 2$ & $\mathrm{CB}$ & $\mathrm{F}$ & $\mathrm{T} 2$ & $\mathrm{CB}$ & $\mathrm{F}$ & $\mathrm{T} 2$ & $\mathrm{CB}$ \\
\hline $100 \%$ & 2 & 2 & 2 & 2 & 2 & 2 & 2 & 2 & 2 & NA & NA & NA & 4 & 4 & 2 \\
\hline $90 \%$ & 2 & 2 & 2 & 2 & 2 & 2 & 2 & 2 & 2 & NA & NA & NA & 4 & 4 & 2 \\
\hline $80 \%$ & 2 & 2 & 2 & 2 & 2 & 2 & 2 & 2 & 2 & NA & NA & NA & 4 & 4 & 2 \\
\hline $65 \%$ & 2 & 2 & 2 & 2 & 2 & 2 & 2 & 2 & 2 & NA & NA & NA & 4 & 4 & 2 \\
\hline $50 \%$ & 2 & 2 & 2 & 3 & 3 & 3 & 3 & 3 & 3 & NA & NA & NA & 2 & 2 & 2 \\
\hline $45 \%$ & 3 & 3 & 3 & 3 & 3 & 3 & 3 & 3 & 3 & NA & NA & NA & 2 & 2 & 2 \\
\hline
\end{tabular}

Fuzzy logic: fixed (F), type-2 (T2), or cond.-based (CB).

(c)

\begin{tabular}{|c|c|c|c|c|c|c|c|c|c|c|c|c|c|c|c|}
\hline \multirow{3}{*}{ Initial batt. power } & \multicolumn{3}{|c|}{ UGS 1} & \multicolumn{3}{|c|}{ UGS 2} & \multicolumn{3}{|c|}{ UGS 3} & \multicolumn{3}{|c|}{ UGS 4} & \multicolumn{3}{|c|}{ UGS 5} \\
\hline & \multicolumn{3}{|c|}{ Type-1 } & \multicolumn{3}{|c|}{ Type-1 } & \multicolumn{3}{|c|}{ Type-1 } & \multicolumn{3}{|c|}{ Type-2 } & \multicolumn{3}{|c|}{ Type-2 } \\
\hline & $\mathrm{F}$ & $\mathrm{T} 2$ & $\mathrm{CB}$ & $\mathrm{F}$ & $\mathrm{T} 2$ & $\mathrm{CB}$ & $\mathrm{F}$ & $\mathrm{T} 2$ & $\mathrm{CB}$ & $\mathrm{F}$ & $\mathrm{T} 2$ & $\mathrm{CB}$ & $\mathrm{F}$ & $\mathrm{T} 2$ & $\mathrm{CB}$ \\
\hline $100 \%$ & NA & NA & NA & 2 & 2 & 2 & 2 & 2 & 2 & 4 & 4 & 2 & 4 & 4 & 2 \\
\hline $90 \%$ & NA & NA & NA & 2 & 2 & 2 & 2 & 2 & 2 & 4 & 4 & 2 & 4 & 4 & 2 \\
\hline $80 \%$ & NA & NA & NA & 2 & 2 & 2 & 2 & 2 & 2 & 4 & 4 & 2 & 4 & 4 & 2 \\
\hline $65 \%$ & NA & NA & NA & 2 & 2 & 2 & 2 & 2 & 2 & 4 & 4 & 2 & 4 & 4 & 2 \\
\hline $50 \%$ & NA & NA & NA & 2 & 2 & 3 & 2 & 2 & 3 & 2 & 2 & 2 & 2 & 2 & 2 \\
\hline $45 \%$ & NA & NA & NA & 3 & 3 & 3 & 3 & 3 & 3 & 2 & 2 & 2 & 2 & 2 & 2 \\
\hline
\end{tabular}

Fuzzy logic: fixed (F), type-2 (T2), or cond.-based (CB).

section. In the type-2 fuzzy logic system, the baseline system was modified so that the acoustic sensor model incorporated uncertainty of the sensor in the placements of the acoustic receivers. Finally, in the condition-based system, there is a modification to sensor capabilities to account for season and maintenance, as described in Table 3. Results for the selection of the wake-up sensor are shown in Section 6.1. Results for the selection of the tracking sensors are shown in Section 6.2. Finally, Section 6.3 shows overall power consumption results for the scenario.

6.1. Wake-Up Sensor Selection Results. Tables 4(a)-4(c) show the decisions for different battery levels for the wake-up step for targets 1,4 , and 6 , respectively, in each of the three variations on the resource management system. For the wake-up selection, the decision is solely based on the power consumption and the accuracy of the classification capabilities of the sensor.

When the battery power is sufficient, the best classification sensor on each UGS is chosen. However, when the battery power is lower, the selection changes. At $50 \%$, the EO sensor is considered too costly and the type-2 UGS switches to the acoustic sensor. Similarly, at 45\% initial batter power, the type-1 UGS changes to the chemical sensor for initial classification. For wake-up selection, there is no change between the baseline system and the type- 2 case. For the condition-based variation, the type-2 UGS now always utilizes its acoustic sensor. The point of interest is at $50 \%$ 
TABLE 5: (a) Selection of tracking sensors at UGS for fixed, type-2, and condition-based fuzzy logic: target 1. (b) Selection of tracking sensors at UGS for fixed, type-2, and condition-based fuzzy logic: target 4. (c) Selection of tracking sensors at UGS for fixed, type-2, and condition-based fuzzy logic: target 6.

(a)

\begin{tabular}{|c|c|c|c|c|c|c|c|c|c|c|c|c|c|c|c|}
\hline \multirow{3}{*}{ Initial batt. power } & \multicolumn{3}{|c|}{ UGS 1} & \multicolumn{3}{|c|}{ UGS 2} & \multicolumn{3}{|c|}{ UGS 3} & \multicolumn{3}{|c|}{ UGS 4} & \multicolumn{3}{|c|}{ UGS 5} \\
\hline & \multicolumn{3}{|c|}{ Type-1 } & \multicolumn{3}{|c|}{ Type-1 } & \multicolumn{3}{|c|}{ Type-1 } & \multicolumn{3}{|c|}{ Type-2 } & \multicolumn{3}{|c|}{ Type-2 } \\
\hline & $\mathrm{F}$ & $\mathrm{T} 2$ & $\mathrm{CB}$ & $\mathrm{F}$ & $\mathrm{T} 2$ & $\mathrm{CB}$ & $\mathrm{F}$ & $\mathrm{T} 2$ & $\mathrm{CB}$ & $\mathrm{F}$ & $\mathrm{T} 2$ & $\mathrm{CB}$ & $\mathrm{F}$ & $\mathrm{T} 2$ & $\mathrm{CB}$ \\
\hline $100 \%$ & 2,3 & 2,3 & 2,3 & 2,3 & 2,3 & 2,3 & 2,3 & 2,3 & 2,3 & 2,4 & 2,4 & 2,4 & $\mathrm{NA}$ & NA & NA \\
\hline $90 \%$ & 2,3 & 2,3 & 2,3 & 2,3 & 2,3 & 2,3 & 2,3 & 2,3 & 2,3 & 4 & 4 & 4 & NA & NA & NA \\
\hline $80 \%$ & 2,3 & 2,3 & 2,3 & 2,3 & 2,3 & 2,3 & 2,3 & 2,3 & 2,3 & 4 & 4 & 4 & NA & NA & NA \\
\hline $65 \%$ & 2,3 & 2,3 & 2,3 & 2,3 & 2,3 & 2,3 & 2,3 & 2,3 & 2,3 & 4 & 4 & 4 & NA & NA & NA \\
\hline $50 \%$ & 2 & 2,3 & 2 & 2 & 2,3 & 2 & 2 & 2,3 & 2 & 2 & 2 & 2 & NA & NA & NA \\
\hline $45 \%$ & 2 & 3 & 2 & 2 & 3 & 2 & 2 & 3 & 2 & 2 & 2 & 2 & NA & NA & NA \\
\hline
\end{tabular}

Fuzzy logic: fixed (F), type-2 (T2), or cond.-based (CB).

(b)

\begin{tabular}{|c|c|c|c|c|c|c|c|c|c|c|c|c|c|c|c|}
\hline \multirow{3}{*}{ Initial batt. power } & \multicolumn{3}{|c|}{ UGS 1} & \multicolumn{3}{|c|}{ UGS 2} & \multicolumn{3}{|c|}{ UGS 3} & \multicolumn{3}{|c|}{ UGS 4} & \multicolumn{3}{|c|}{ UGS 5} \\
\hline & & Type & & & Type- & & & Type- & & & ype-2 & & & ype- & \\
\hline & $\mathrm{F}$ & $\mathrm{T} 2$ & $\mathrm{CB}$ & $\mathrm{F}$ & $\mathrm{T} 2$ & $\mathrm{CB}$ & $\mathrm{F}$ & $\mathrm{T} 2$ & $\mathrm{CB}$ & $\mathrm{F}$ & $\mathrm{T} 2$ & $\mathrm{CB}$ & $\mathrm{F}$ & $\mathrm{T} 2$ & $\mathrm{CB}$ \\
\hline $100 \%$ & 2,3 & 2,3 & 2,3 & 2,3 & 2,3 & 2,3 & 2,3 & 2,3 & 2,3 & NA & NA & NA & 2,4 & 2,4 & 2,4 \\
\hline $90 \%$ & 2,3 & 2,3 & 2,3 & 2,3 & 2,3 & 2,3 & 2,3 & 2,3 & 2,3 & NA & NA & NA & 4 & 4 & 2 \\
\hline $80 \%$ & 2,3 & 2,3 & 2,3 & 2,3 & 2,3 & 2,3 & 2,3 & 2,3 & 2,3 & NA & NA & NA & 4 & 4 & 2 \\
\hline $65 \%$ & 2,3 & 2,3 & 2,3 & 2,3 & 2,3 & 2,3 & 2,3 & 2,3 & 2,3 & NA & NA & NA & 4 & 4 & 2 \\
\hline $50 \%$ & 2 & 2,3 & 2 & 2 & 2,3 & 2 & 2 & 2,3 & 2 & NA & NA & NA & 2 & 2 & 2 \\
\hline $45 \%$ & 2 & 3 & 2 & 2 & 3 & 2 & 2 & 3 & 2 & NA & NA & NA & 2 & 2 & 2 \\
\hline
\end{tabular}

Fuzzy logic: fixed (F), type-2 (T2), or cond.-based (CB).

(c)

\begin{tabular}{|c|c|c|c|c|c|c|c|c|c|c|c|c|c|c|c|}
\hline \multirow{3}{*}{ Initial batt. power } & \multicolumn{3}{|c|}{ UGS 1} & \multicolumn{3}{|c|}{ UGS 2} & \multicolumn{3}{|c|}{ UGS 3} & \multicolumn{3}{|c|}{ UGS 4} & \multicolumn{3}{|c|}{ UGS 5} \\
\hline & & Type- & & & Type- & & & Type- & & & Гуре- & & & ype- & \\
\hline & $\mathrm{F}$ & $\mathrm{T} 2$ & $\mathrm{CB}$ & $\mathrm{F}$ & $\mathrm{T} 2$ & $\mathrm{CB}$ & $\mathrm{F}$ & $\mathrm{T} 2$ & $\mathrm{CB}$ & $\mathrm{F}$ & $\mathrm{T} 2$ & $\mathrm{CB}$ & $\mathrm{F}$ & $\mathrm{T} 2$ & $\mathrm{CB}$ \\
\hline $100 \%$ & $\mathrm{NA}$ & NA & NA & 2,3 & 2,3 & 2,3 & 2,3 & 2,3 & 2,3 & 2,4 & 2,4 & 2,4 & 2,4 & 2,4 & 2,4 \\
\hline $90 \%$ & NA & NA & NA & 2,3 & 2,3 & 2,3 & 2,3 & 2,3 & 2,3 & 4 & 4 & 4 & 4 & 4 & 4 \\
\hline $80 \%$ & NA & NA & NA & 2,3 & 2,3 & 2,3 & 2,3 & 2,3 & 2,3 & 4 & 4 & 4 & 4 & 4 & 4 \\
\hline $65 \%$ & NA & NA & NA & No & No & No & No & No & No & 4 & 4 & No & 4 & 4 & No \\
\hline $50 \%$ & NA & NA & NA & No & No & No & No & No & No & No & No & No & No & No & No \\
\hline $45 \%$ & NA & NA & NA & No & No & No & No & No & No & No & No & No & No & No & No \\
\hline
\end{tabular}

Fuzzy logic: fixed (F), type-2 (T2), or cond.-based (CB).

initial power, and the type-1 UGS uses its chemical sensor for targets 4 and 6 after the battery power falls after target 1 .

6.2. Tracking Sensor Selection Results. Tables 5(a)-5(c) show the results of the target tracking sensor selections after initial classification is made. Here, the selections are based on the sensor's capabilities and power consumption along with the mission importance of the targets. The initial battery level is defined for the wake-up step for the first target. Power is consumed based on the decision being made. For this analysis, it was assumed that the wake-up classification was correct. This means that at lower battery levels power usage becomes more critical. The tables also indicate, as expected, that the selection of the sensors is the same as the game is the same for each UGS. This may be different if the UGS was working as a network instead of independently.

The results indicate that the resource manager selects both sensors on the type-1 UGS for all targets while there is power but then shuts off the sensors as the tracking capabilities are not worth the power expenditure as the battery power diminishes. The EO accuracy is usually considered enough for the power usage and that not enough capabilities are added using the acoustic sensor. The point of interest for the low-level target, target 6 , occurs when the EO sensor is still in operations while the type-1 UGS decides to ignore the target. This indicates that the relationship between mission importance and system capabilities is not as straightforward as would be assumed. 
TABLE 6: Battery consumption (mA) for each UGS based on initial available power.

\begin{tabular}{|c|c|c|c|c|c|c|c|c|c|c|c|c|c|c|c|}
\hline \multirow{2}{*}{$\begin{array}{l}\text { Initial batt. } \\
\text { power }\end{array}$} & \multicolumn{3}{|c|}{ UGS 1 (type-1) } & \multicolumn{3}{|c|}{ UGS 2 (type-1) } & \multicolumn{3}{|c|}{ UGS 3 (type-1) } & \multicolumn{3}{|c|}{ UGS 4 (type-2) } & \multicolumn{3}{|c|}{ UGS 5 (type-2) } \\
\hline & xed & ne & & yed & ? & & xed & Tyr & & ixed & Type-2 & & ixed & & \\
\hline $00 \%$ & & & & & & & & & & & & & & & \\
\hline 00 & & & & & & & & & & & & & & & \\
\hline $80 \%$ & & & & $\begin{array}{c}785 \\
/ 1.0 \%\end{array}$ & $\begin{array}{c}785 \\
/ 1.0 \%\end{array}$ & & $\begin{array}{c}810 \\
/ 1.0 \%\end{array}$ & & & & & & $\begin{array}{c}917 \\
/ 1.1 \%\end{array}$ & & \\
\hline $65 \%$ & $\begin{array}{c}683 \\
/ 1.0 \%\end{array}$ & & $\begin{array}{c}683 \\
/ 1.0 \%\end{array}$ & $\begin{array}{c}708 \\
/ 1.1 \%\end{array}$ & $\begin{array}{c}708 \\
/ 1.1 \%\end{array}$ & & $\begin{array}{c}664 \\
/ 1.0 \%\end{array}$ & $\begin{array}{c}664 \\
/ 1.0 \%\end{array}$ & & $\begin{array}{c}653 \\
/ 1.0 \%\end{array}$ & $\begin{array}{c}653 \\
/ 1.0 \%\end{array}$ & & $\begin{array}{c}868 \\
/ 1.4 \%\end{array}$ & & \\
\hline $50 \%$ & $\begin{array}{c}565 \\
/ 1.2 \%\end{array}$ & $\begin{array}{c}598 \\
/ 1.2 \%\end{array}$ & $\begin{array}{c}565 \\
/ 1.2 \%\end{array}$ & $\begin{array}{c}596 \\
/ 1.2 \%\end{array}$ & $\begin{array}{c}637 \\
/ 1.3 \%\end{array}$ & $\begin{array}{l}596 \\
/ 1.2 \%\end{array}$ & $\begin{array}{c}559 \\
/ 1.1 \%\end{array}$ & $\begin{array}{c}593 \\
/ 1.2 \%\end{array}$ & $\begin{array}{l}559 \\
/ 1.1 \%\end{array}$ & $\begin{array}{c}447 \\
/ 0.9 \%\end{array}$ & $\begin{array}{c}447 \\
/ 0.9 \%\end{array}$ & $\begin{array}{c}447 \\
/ 0.9 \%\end{array}$ & $\begin{array}{c}652 \\
/ 1.3 \%\end{array}$ & $\begin{array}{c}652 \\
/ 1.3 \%\end{array}$ & $\begin{array}{c}652 \\
/ 1.3 \%\end{array}$ \\
\hline $45 \%$ & $\begin{array}{c}547 \\
/ 1.2 \%\end{array}$ & $\begin{array}{c}423 \\
/ 1.0 \%\end{array}$ & $\begin{array}{c}547 \\
/ 1.2 \%\end{array}$ & $\begin{array}{c}590 \\
/ 1.3 \%\end{array}$ & $\begin{array}{c}431 \\
/ 1.0 \%\end{array}$ & $\begin{array}{c}590 \\
/ 1.3 \%\end{array}$ & $\begin{array}{c}553 \\
/ 1.3 \%\end{array}$ & $\begin{array}{c}423 \\
/ 1.0 \%\end{array}$ & $\begin{array}{c}553 \\
/ 1.3 \%\end{array}$ & $\begin{array}{c}447 \\
/ 1.0 \%\end{array}$ & $\begin{array}{c}447 \\
/ 1.0 \%\end{array}$ & $\begin{array}{c}447 \\
/ 1.0 \%\end{array}$ & $\begin{array}{c}578 \\
/ 1.3 \%\end{array}$ & $\begin{array}{c}578 \\
/ 1.3 \%\end{array}$ & $\begin{array}{c}578 \\
/ 1.3 \%\end{array}$ \\
\hline
\end{tabular}

The difference between the type-2 fuzzy approach and the baseline occurs in the $50 \%$ and $45 \%$ initial battery reserve. In this case, the acoustic model's uncertainty allows it to continue operation longer than in the baseline approach. The key is that the uncertainty is now modeled.

The condition-based results indicate that the resource manager selects both sensors on the type-1 UGS for all targets while there is power but then shuts off the sensors as the tracking capabilities are not worth the power expenditure as the battery power diminishes. With the reduction in the EO capability, it shuts off for lesser important targets not considered worth the power, such as target 6 . Also the use of both sensors on the type-2 UGS is not worth the power consumption and that selection goes away more quickly.

6.3. Power Consumption Results. Each fuzzy approach to generate the game decision scores is now compared in terms of the resulting battery consumption in Table 6. The number of $\mathrm{mA}$ drained from the battery is shown along with the percentage of total power used. The table comparison provides an interesting operational decision. The type- 2 fuzzy logic, although applicable to both types of UGS, is useful only for the type-1 UGS when it has a beneficial effect as designed for low initial power availability. In fact at 50\%, a jump in power consumption is noted. The condition-based fuzzy logic was designed only for the type-2 UGS. It works well by lowering the power consumption for high initial battery power levels (above 50\%). In other operations, a basic fuzzy logic approach works just as well.

Without expert tuning, the basic fuzzy logic would be the best choice overall. However, based on the conditions and UGS type used it appears that switching between the different modes could be beneficial.

\section{Conclusions}

The resource management system has been shown to have the ability to work with a multisensor UGS platform. The incorporation of uncertainty into the fuzzy models is an important addition as it better models the system for a posteriori changes in the system model once it is placed. However, this benefit is not a constant through the scenario. To better model these changes, more analysis of the system is required. The cost of modeling the fuzzy logic may preclude such operations.

Many other implementation enhancements are possible. As the system evolves, implementation of these changes such as networking the UGS and using the current operational UGS results to bypass the wake-up step are being pursued.

\section{References}

[1] S. C. Stubberud and K. A. Kramer, "Sensor network activation with a fuzzy-based game theory," in Proceedings of the IEEE International Instrumentation and Measurement Technology Conference, pp. 1133-1138, Graz, Austria, 2012.

[2] S. C. Stubberud and K. A. Kramer, "Unattended ground sensor resource allocation using a fuzzy game," in Proceedings of the International Conference on Systems Engineering (ICSE '12), pp. 1-6, Coventry, UK, 2012.

[3] S. C. Stubberud and K. A. Kramer, "Resource allocation with uncertain sensor models," in Proceedings of the IEEE International Conference on Fuzzy Systems, pp. 1-7, Brisbane, Australia, 2012.

[4] R. R. Brooks, P. Ramanathan, and A. M. Sayeed, "Distributed target classification and tracking in sensor networks," Proceedings of the IEEE, vol. 91, no. 8, pp. 1163-1171, 2003.

[5] H. K. Cordell, C. J. Betz, G. Green, and M. Owens, "Off-highway vehicle recreation in the United States, regions, and states: a national report from the national survey on recreation and the environment (NSRE)," US Forest Service, pp. 1-2, 2005.

[6] M. El Gammal and M. Eltoweissy, "Towards aware, adaptive and autonomic sensor-actuator networks," in Proceedings of the 5th IEEE international Conference on Self-Adaptive and SelfOrganizing Systems, pp. 210-211, Ann Arbor, Mich, USA, 2011.

[7] D. S. Hammond, V. Gond, B. De Thoisy, P. M. Forget, and B. P. E. DeDijn, "Causes and consequences of a tropical forest gold rush in the Guiana Shield, South America," Ambio, vol. 36, no. 8, pp. 661-670, 2007. 
[8] M. Mallery, "Marijuana National Forest: Encroachment on Public Lands for Cannabis Cultivation," Berkeley Undergraduate Journal, vol. 23, no. 2, pp. 1-50, 2010.

[9] W. F. Laurance, "A crisis in the making: responses of Amazonian forests to land use and climate change," Trends in Ecology and Evolution, vol. 13, no. 10, pp. 411-415, 1998.

[10] J. F. Tynon and D. J. Chavez, "Crime in national forecasts: a call for research," Journal of Forestry, vol. 104, no. 3, pp. 154-157, 2006.

[11] K. J. Hammer, "Gate-crashing: road closure gates cannot effectively eliminate trespass," Swan View Coalition Report, pp. 1-8, 2001.

[12] "Ground Sensor Equipment (BSA)," Defense Update, 2006, http://defense-update.com/products/b/BSA-UGS.htm.

[13] J. M. Mendel, R. I. John, and F. Liu, "Interval type-2 fuzzy logic systems made simple," IEEE Transactions on Fuzzy Systems, vol. 14, no. 6, pp. 808-821, 2006.

[14] X. Hu, P. Bonissone, and R. Subbu, "Robust model selection decision-making using a fuzzy supervisory approach," in Proceedings of the IEEE Symposium on Computational Intelligence in Multi-Criteria Decision-Making (MCDM '09), pp. 126-132, April 2009.

[15] D. Zhai and J. Mendel, "Centroid of a general type-2 fuzzy set computed by means of the centroid flow algorithm," in Proceedings of the IEEE International Conference on Fuzzy Systems, pp. 1-8, 2011.

[16] A. Ezekiel, "Advancements in ground moving target identification in radar vision," in Proceedings of the National Fire Control Symposium, pp. 1-5, 2011.

[17] S. Blackman, Multiple-Target Tracking with Radar Applications, Artech House, Norwood, Mass, USA, 1986. 

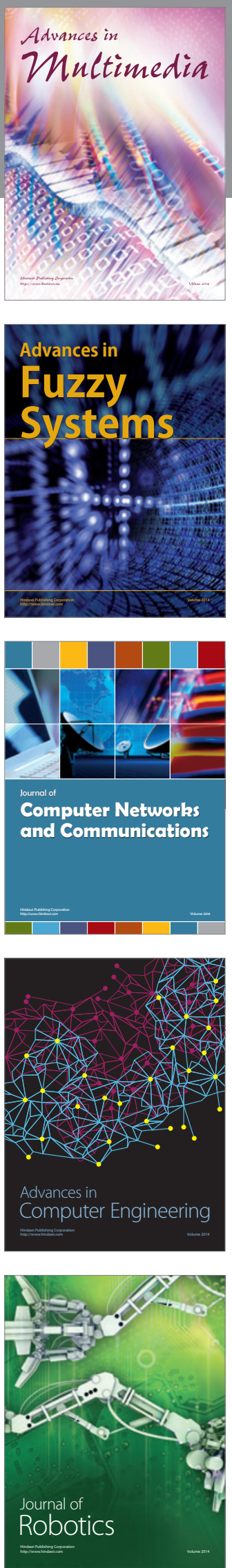

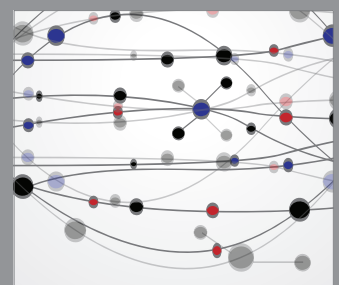

The Scientific World Journal
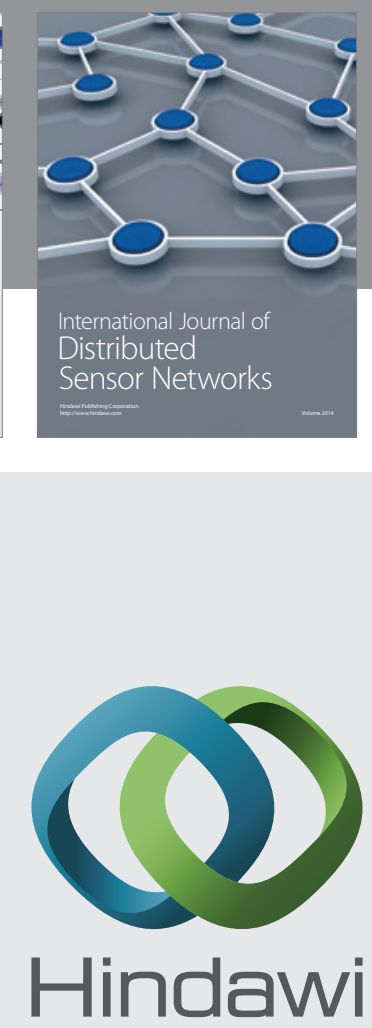

Submit your manuscripts at

http://www.hindawi.com
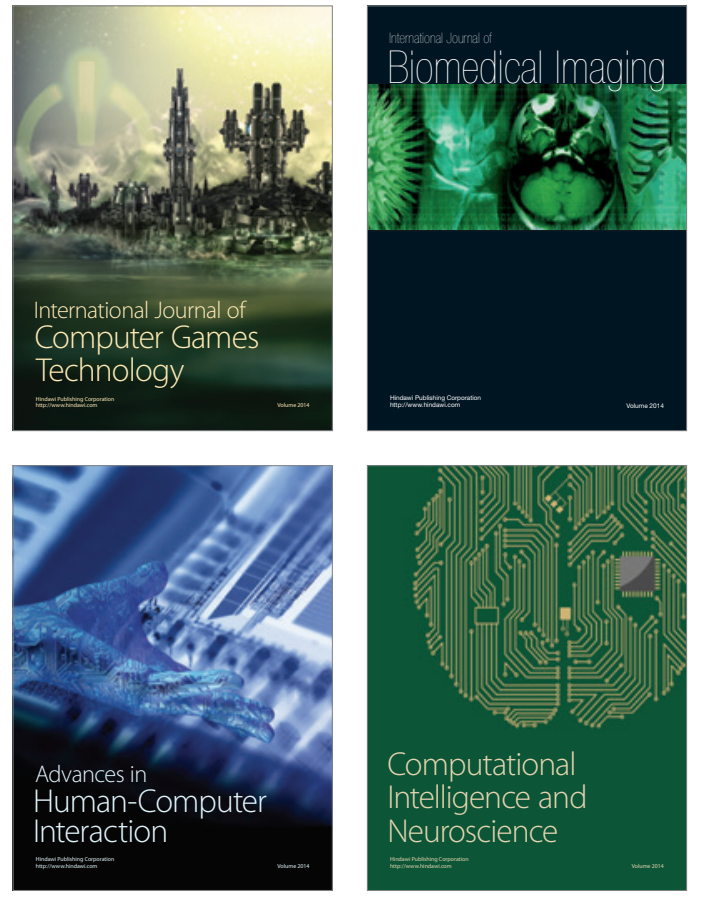
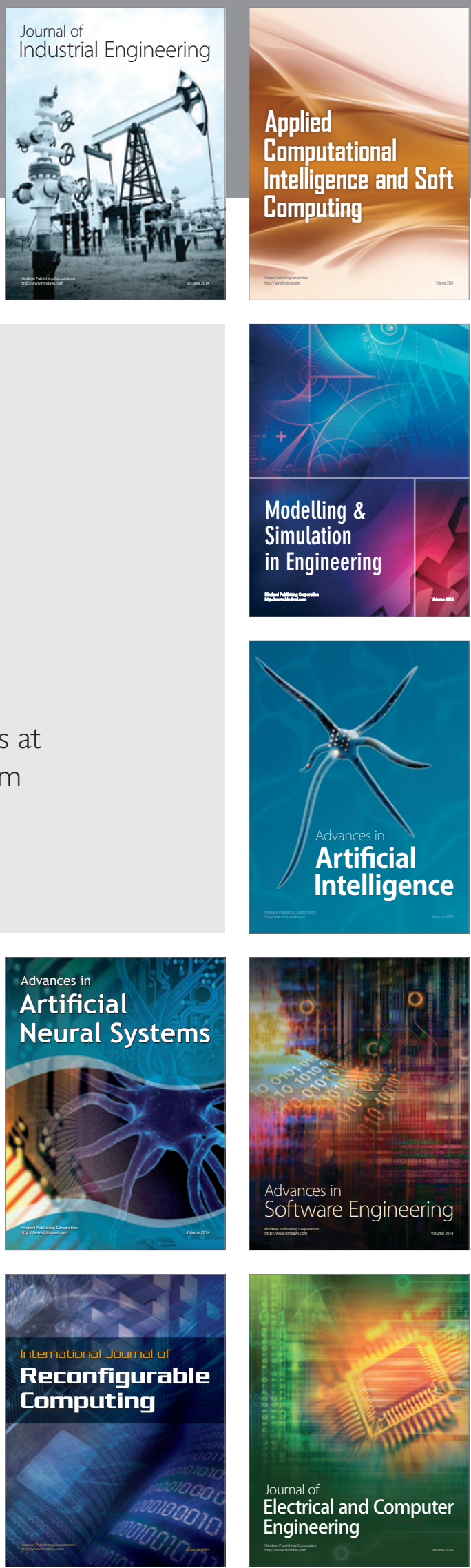